\title{
LASER MICROSTRUCTURE MODIFICATION OF METALLIC MATERIALS
}

\author{
B. Major, R. Ciach \\ Institute of Metallurgy and Materials Science, Polish Academy of Sciences \\ Reymonta 25, 30-059 Kraków, Poland \\ R. EBNER AND F. JEgLiTSCH \\ Christian Doppler Laboratory for "Laser Application in Materials Research" \\ at the Institute for Metals Technology and Materials Testing \\ Montanuniversity Leoben, Austria
}

Structure changes in laser constituted surface layers of aluminium alloys of the systems: $\mathrm{Al}-\mathrm{Zn}, \mathrm{Al}-\mathrm{Fe}, \mathrm{Al}-\mathrm{Fe}-\mathrm{Ni}, \mathrm{Al}-\mathrm{Si}$ were examined. Significant structure refinements and even formation of characteristic precipitates for rapidly quenched microstructure were found. Fine martensitic microstructure was observed in constructional steels of the types: $\mathrm{X} 45 \mathrm{CrSi} 92$ (H9S2) and C50 (50G) subject to a laser modification. The study of influence of the chemical composition on the solidification structure and hardness was carried out on a steel 45, as well as on a high speed steel M2 (SW7M), by laser alloying using carbides of the types: $\mathrm{VC}, \mathrm{Mo}_{2} \mathrm{C}$ and the borides of the types: $\mathrm{CrB}, \mathrm{VB}_{2}, \mathrm{~B}_{4} \mathrm{C}$. Thermodynamic calculations of phase diagrams were made to predict the changes of the constitution due to laser alloying. A comparison of the solidification structures and the calculated phase diagrams revealed a good agreement, especially for carbides. Boride alloying led to very complex microstructures consisting of various metallic and intermetallic phases.

PACS numbers: $52.50 . \mathrm{Jm}, 64.70 . \mathrm{Dv}$

\section{Introduction}

Surface treatment seems to offer the chance to save strategic materials or to produce improved components with idealised surface and bulk properties $[1,2]$. Alloying modification of the surface layer can be realized by application of technologies which enable high cooling rates during solidification, e.g. powder metallurgy or surface melting techniques. The latter, like laser or electron beam melting offer the widest possibilities for the modification of the structure in surface near - regions [3-11]. Laser remelting and laser alloying can be used to create supersaturated and highly alloyed materials with novel structure. Most of the benefit effect of a laser treatment can be attributed to specific solidification fine structure. The high-melt-pool temperature, resulting from a high power density of laser beam, 
enables the dissolution of even thermodynamically stable intermetallic phases and formation of metastable phases due to the high cooling rates, which in consequence could offer new possibilities in alloy design. The development of materials occurs predominantly on an empirical basis, because our experience with rapidly solidified laser alloyed structures is so far limited, thus attempts which develop the knowledge on this process seem to be valuable.

The authors present their own experimental results concerning a contribution of laser remelting and laser alloying to the morphology and mechanical properties of materials in a wide range of compositions. Examinations have been carried out on aluminium alloys, constructional steels, as well as a high speed steel, and a goal was to establish a scientific basis for the possible application in industry.

\section{Experimental}

\subsection{Material and method of examinations}

The studies were performed on the aluminium base alloys such as: AlZn30, AlZn5Mg3Cu1, AlFe6, AlFe6Ni2, AlSi12 (content in wt.\%), constructional steels: $\mathrm{Ck} 45$, X45CrSi93 (H9S2), C50 (50G), as well as a high speed steel (HSS) M2 (SW7M). The materials were used in an annealed condition.

Carbide laser alloying with $\mathrm{VC}$ and $\mathrm{Mo}_{2} \mathrm{C}$ was performed on M2 HSS. Boride laser alloying was carried out using $\mathrm{CrB}, \mathrm{VB}_{2}$ on $\mathrm{M} 2 \mathrm{HSS}$ and $\mathrm{CrB}, \mathrm{VB}_{2}$ and $\mathrm{B}_{4} \mathrm{C}$ on Ck45. A laser treatment of these materials was performed with $\mathrm{cw} \mathrm{CO}_{2} 2.5 \mathrm{~kW}$ laser working at the Institute of Fundamental Technological Research, Pol. Acad. of Sci. in Warsaw (remelting of aluminium alloys and constructional steels) and using $\mathrm{cw} \mathrm{CO}_{2} 2.5 \mathrm{~kW}$ laser working at Christian Doppler Laboratory at Montanuniversity Leoben in Austria (carbide and boride laser alloying of M2 HSS and $\mathrm{Ck} 45$ ). Calculations of phase diagrams of multicomponent systems were performed using Thermo-Calc program which was at disposal at Montanuniversity Leoben. Microstructural investigations were performed by means of scanning electron microscopy (SEM) and transmission electron microscopy (TEM) where the chemical composition was determined using Link energy dispersive X-ray system which was attached to the SEM and TEM. Phase analysis of the complex structures were carried out using the Philips X-ray diffraction (XRD) apparatus working with the APD program.

\subsection{Results and discussion}

\subsubsection{Laser modification by remelting of aluminium alloys}

The details of the solidification process were learnt from the AlZn30 alloy examinations after laser remelting (Fig. 1). The process proceeds by an epitaxial regrowth of partially melted grains into the constitutionally supercooled melt in the direction of the local temperature gradient. At the onset of solidification, the supercooled layer of melt adjacent to the planar interface is separated into Zn-rich droplets solidifying later at the eutectic temperature with the development of many plate-like $\beta$ precipitates from each droplet. A subsequently increased solidification rate leads to the formation of irregular and later columnar dendritic cells elongated in the direction of the temperature gradient [12]. The microstructure of AlZn5Mg3 


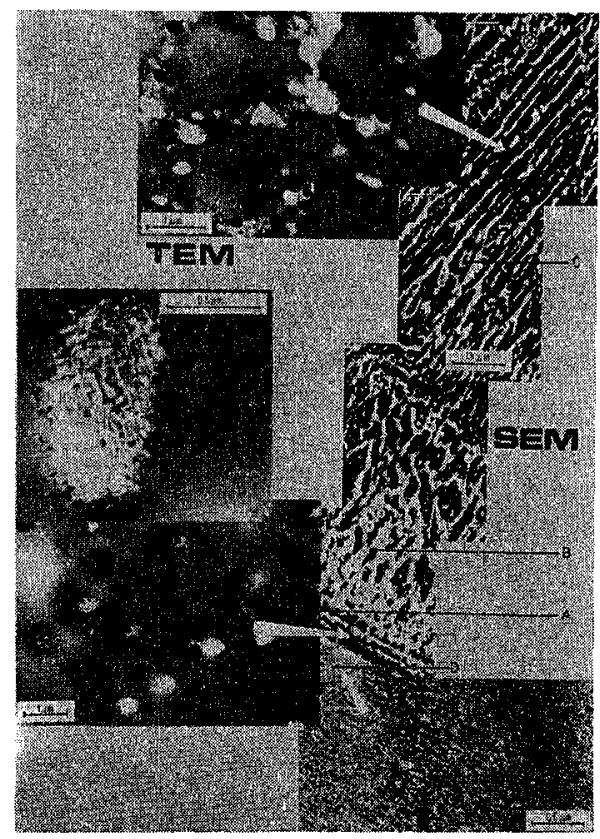

Fig. 1. SEM of a cross-section through the solidified pool and TEM details using foils cut parallel to specimen surface from layers of various depths below the surface. (A) Section with frozen droplets, (B) and (C) sections perpendicular to dendrite axes, (D) unmelted substrate.
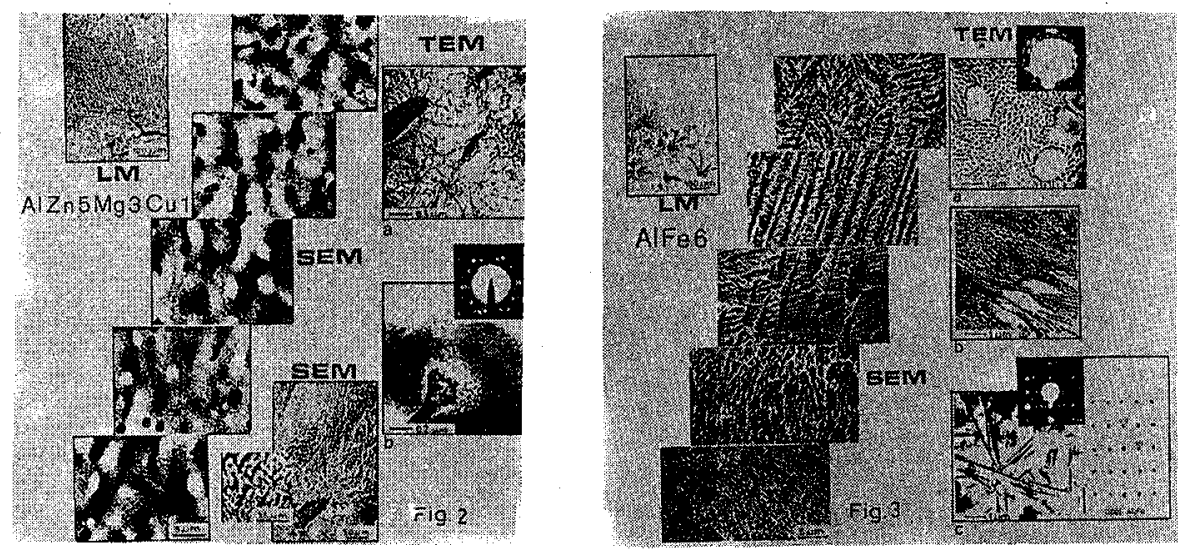

Fig. 2. Microstructure of AlZn5Mg3Cu1 alloy, of the cross-section (LM, SEM) (LM = light microscopy) and parallel to the surface (TEM) of the solidified pool, after laser remelting. (a) Dislocated matrix, (b) metastable precipitate.

Fig. 3. Microstructure of AlFe6 alloy, of the cross-section (LM, SEM) and parallel to the surface (TEM) of the solidified pool, after laser remelting. (a) Cellular microstructure, (b) lamellar microstructure, (c) needle precipitates. 
alloy shows that a layer of about $50 \mu \mathrm{m}$ thickness having cellular fine-structure was formed during the solidification process after laser remelting. The precipitates with tenfold axes, characteristic of the rapid solidification were also found (Fig. 2). The distribution of $\mathrm{Zn}$ was uniform in the layer. The microstructure of laser remelted layer of alloys from the system Al-Fe (AlFe6, AlFe6Ni2) comprises the micro-dendritic cells elongated in the temperature gradient (Fig. 3). The large precipitates of the $\mathrm{Al}_{3} \mathrm{Fe}$ phase, existing in the as-cast structure, have been considerably refined by laser remelting and rapid solidification. Three types of microstructures were revealed in TEM examinations comprising the $\alpha$ - $\mathrm{Al}$ and $\mathrm{Al}_{3} \mathrm{Fe}$ phases in the cellular, lamellar and needle forms. Structure refinement and formation of the metastable phases were responsible for the stated increase in hardness HV by about three times with respect to the parent material. Laser remelting of an AlSi12 eutectic commercial alloy led to a great refinement of the eutectic structure which was accompanied with an increase in hardness of about two times.

\subsubsection{Laser modification of constructional steels}

Laser remelting of $\mathrm{Ck} 45$ steel caused formation of the fine martensite. Subsequent laser heat treatment, by an overlapping laser track, produced even more fine martensitic structure (Fig. 4). Application of laser remelting to a valve steel $\mathrm{X} 45 \mathrm{CrSi} 93$ (H9S2) caused formation of a lath-type martensite (Fig. 5). A martensitic structure was also observed in C50 (50G) steel after laser remelting. This was

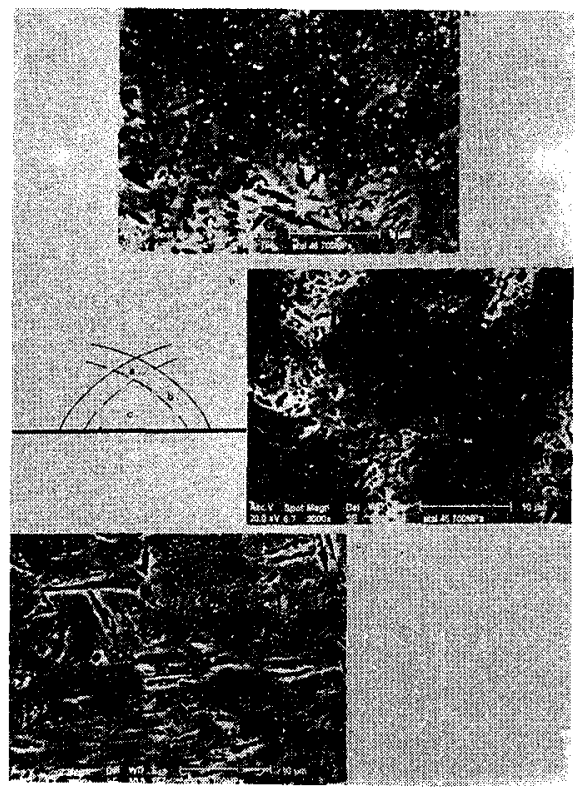

Fig. 4. Microstructure TEM of laser remelted $\mathrm{Ck} 45$ in the laser track overlapping region. (a) Partially remelted (bottom) and heat treated (top) regions, (b) heat treated region, (c) remelted for the second time region. 

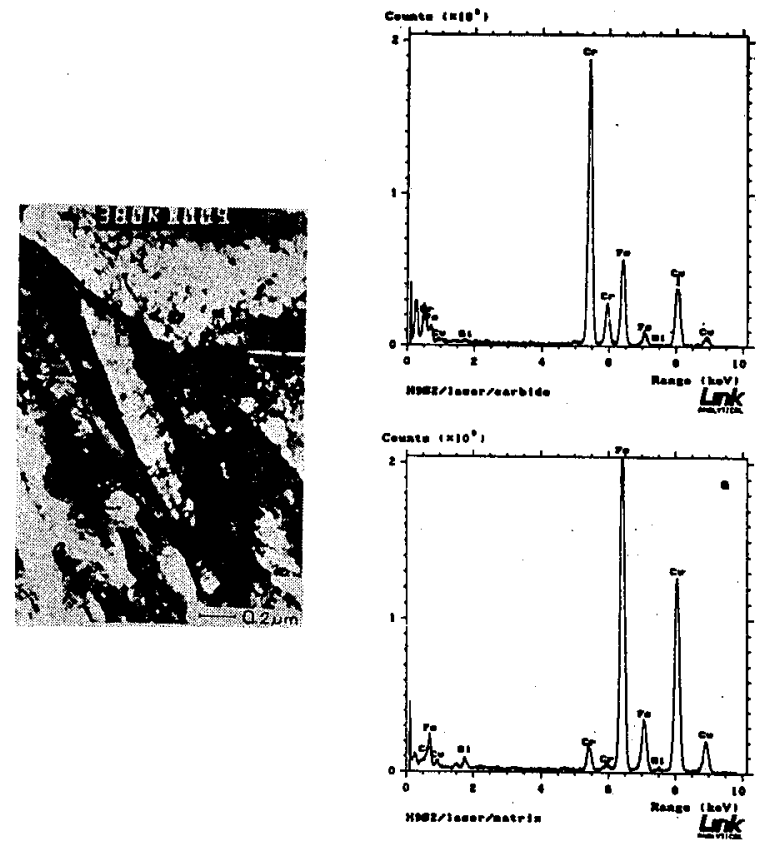

Fig. 5. Microstructure TEM of laser remelted X45CrSi9i (H9S2) steel. (a) EDX microanalysis of matrix, (b) EDX microanalysis of precipitate.

connected with an increase in hardness by about 2-3 times. It is worth noting that a subsequent laser remelting of surface, covered previously with nickel, resulted in austenite formation causing a deep decrease in hardness in this layer which was recovered beneath the austenitic layer to the value characteristic of martensite.

\subsubsection{Carbide and boride laser alloying of carbon and high speed steels}

Vanadium carbide is a thermodynamic stable intermetallic compound (Fig. 6). The vanadium content in common HSS is limited to about 3wt.\%. Application of laser alloying allowed to achieve up to about $40 \mathrm{wt} . \% \mathrm{~V}$ in the laser tracks. Increasing vanadium addition in M2 HSS changes the solidification structure from fine dendrites comprising martensite and retained austenite via two different types of eutectics in the interdendritic space $[8,13,14]$ to primary $\mathrm{MC}$ carbides and two types of eutectic at the high vanadium concentrations (Fig. 7).

Alloying of $\mathrm{M} 2 \mathrm{HSS}$ with $\mathrm{Mo}_{2} \mathrm{C}$ in the range of $5-54 \mathrm{wt} . \%$ Mo leads to the similar effect of diminishing of the dendritic component, as with $\mathrm{VC}$ addition [13-15] (Fig. 8). Primary dendrites of the $\mathrm{M}_{6} \mathrm{C}$ are stated for the hypereutectic compositions while the highest concentrations of Mo shows precipitates of the primary dendrites of $\mathrm{M}_{2} \mathrm{C}$ and causes the ferrite stabilization (Fig. 9).

Increasing boride $\left(\mathrm{CrB}, \mathrm{VB}_{2}\right)$ additions in M2 ISS causes that the volume 


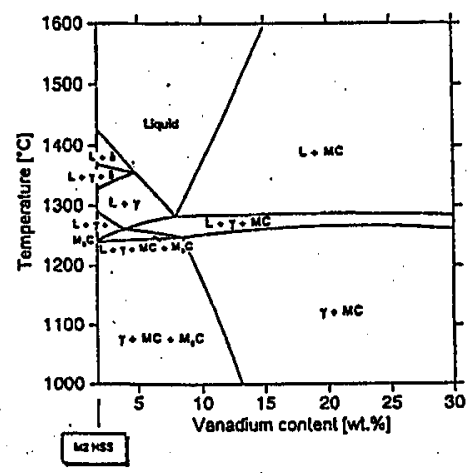

Fig. 6. Cross-section of the multicomponent system M2+VC.
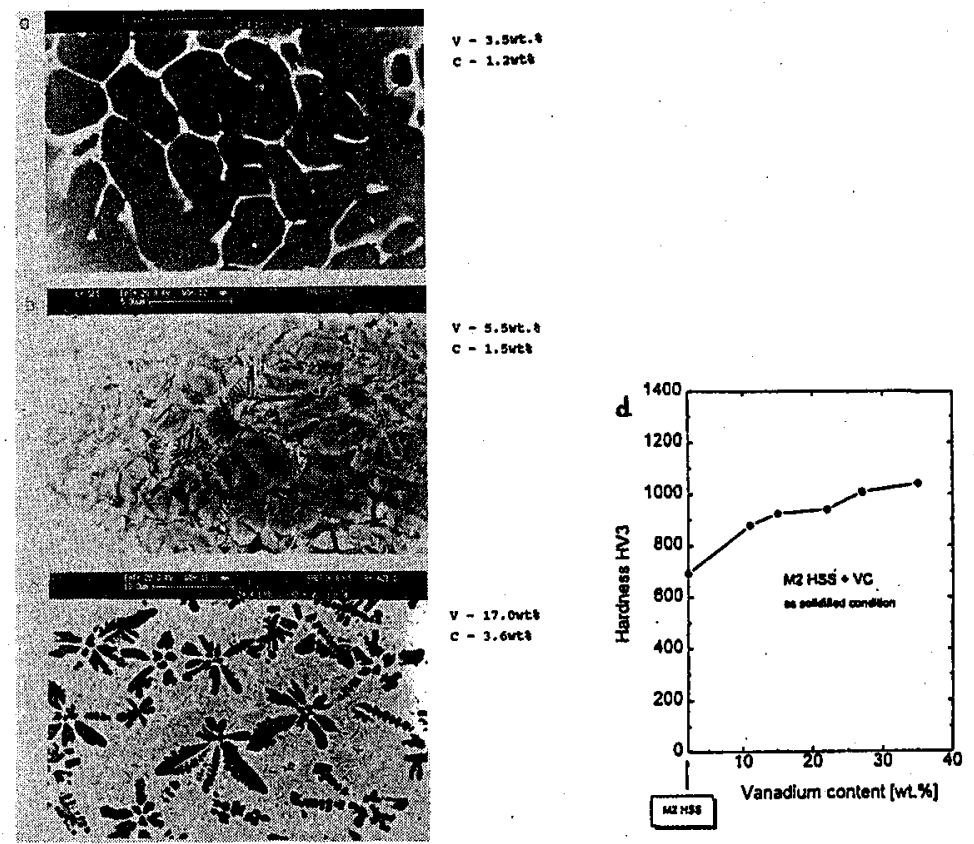

Fig. 7. Microstructures $(a-c)$ and hardness $(d)$ of VC laser alloyed M2 HSS.

fraction of eutectic phases in the interdendritic spaces is high. High additions of borides develop formation of the primary borides of blocky types containing a high amount of $\mathrm{Cr}$ or $\mathrm{V}$, respectively (Fig. 10). Formation of the $\mathrm{MB}$ and $\mathrm{M}_{23} \mathrm{~B}_{6}$ phases was stated in XRD examination $[16,17]$. When depleting the iron-matrix from carbon due to addition of $\mathrm{Cr}$ or $\mathrm{V}$ (because of carbide formation), the ferrite stabilization occurs, which is accompanied with a loss of hardness [16]. Further addition of alloying elements causes again an improvement of the hardness (Fig. 11). Laser alloying of $\mathrm{Ck} 45$ with $\mathrm{CrB}$ by increasing the chromium contents in a 45 


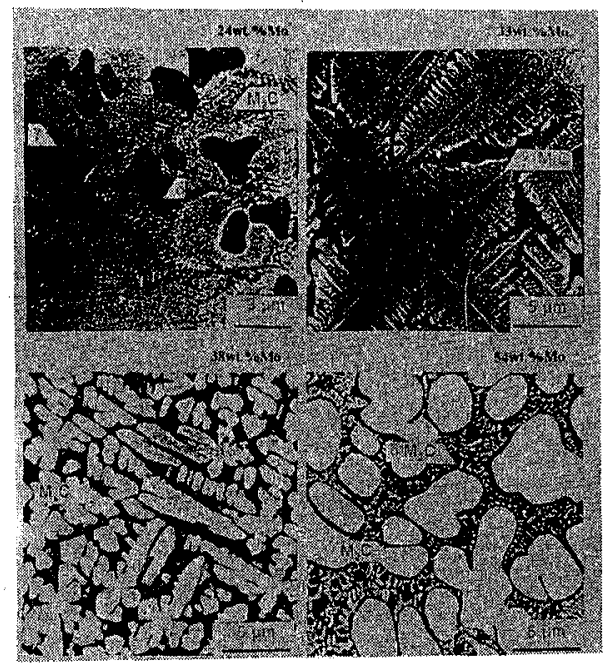

Fig. 8. Microstructures of $\mathrm{Mo}_{2} \mathrm{C}$ laser alloyed $\mathrm{M} 2 \mathrm{HSS}$.

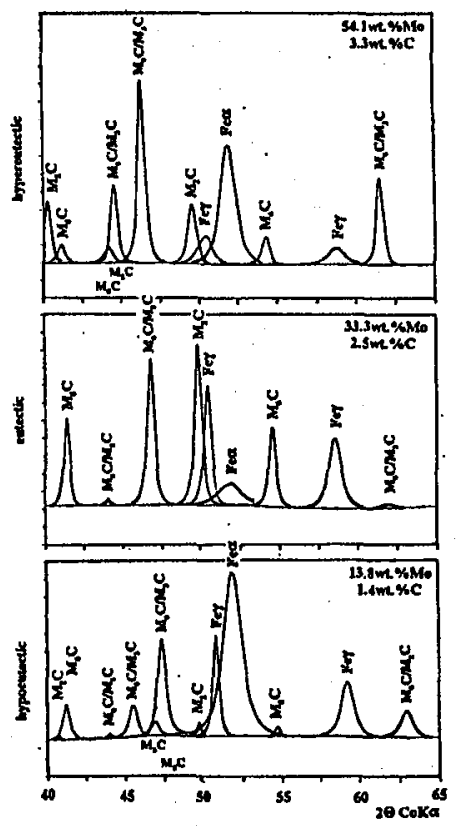

Fig. 9. XRD patterns of $\mathrm{Mo}_{2} \mathrm{C}$ laser alloyed M2 HSS.

steel leads to formation of the high amount of retained austenite. Irregular eutectic comprising the $\alpha^{\prime} / \mathrm{M}_{3}(\mathrm{C}, \mathrm{B}) / \mathrm{M}_{2} \mathrm{~B}$ is stated at about eutectic composition, while the primary borides of the $\mathrm{M}_{2} \mathrm{~B}$-type are formed for the hypereutectic compositions.

The blocky type of borides appears for the Ck45 laser alloying using $\mathrm{VB}_{2}$. 

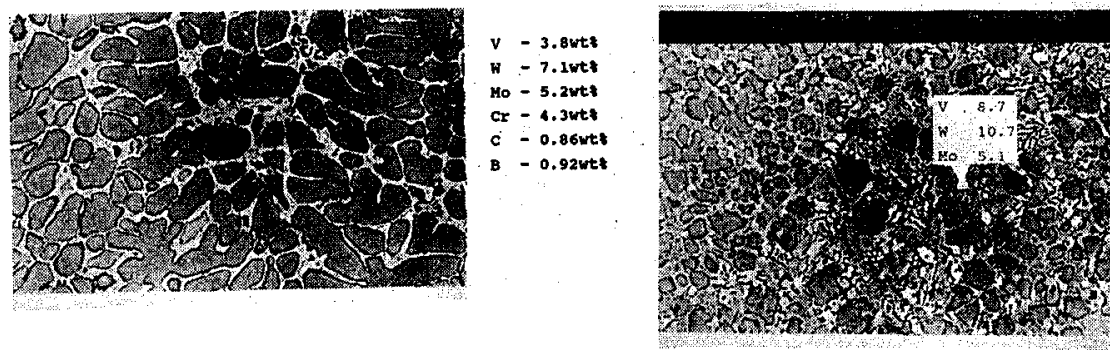

$v-6.2 w t$

W - 6.4wt:

Mo -4.7 wt:

Cr - A.out:

c - 0.83 wet:

B - $1.95 \mathrm{w}$ t:

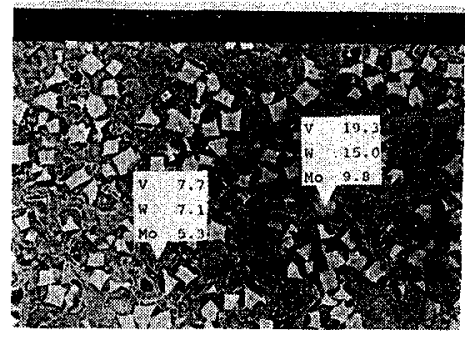

v - 9.4vts

w - 7.2vtz

Mo - 4.5vt:

Cr - 3.9utz

c - 0.7aut:

B - 3.25ut:

Fig. 10. Microstructures SEM of $\mathrm{VB}_{2}$ laser alloyed M2 HSS.
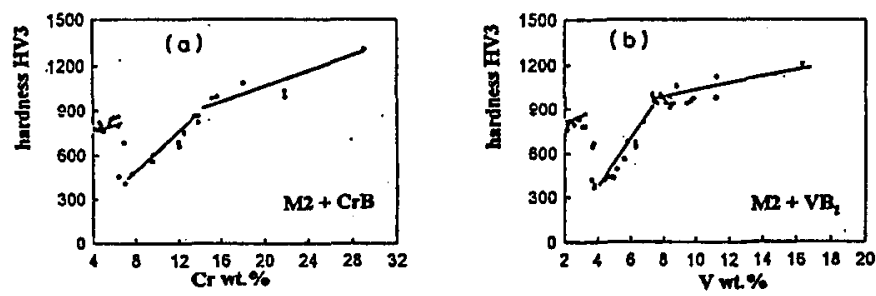

Fig. 11. Hardness $\mathrm{HV} 3$ of $\mathrm{CrB}$ and $\mathrm{VB}_{2}$ laser alloyed M2 HSS.

The $\mathrm{M}_{3} \mathrm{~B}_{2}$ containing of about 50 at. $\% \mathrm{~B}$ is identified for the hypereutectic alloys and beside this phase, the $\mathrm{M}_{2} \mathrm{~B}$ phase with about 30 at. $\% \mathrm{~B}$ is observed for the higher applied concentrations of $\mathrm{V}$ in laser tracks of order of about $14 \mathrm{wt} . \% \mathrm{~V}$ and 6wt.\% B (24at.\% B) (Fig. 12).

Introducing of $\mathrm{B}_{4} \mathrm{C}$ into $\mathrm{Ck} 45$ results in the microstructure in disappearing of the cellular dendritic structure (Fig. 13). The fine eutectic is shown at the composition of about 12.5 at.\% B; 5 at.\% C, while at the hypereutectic composition the primary precipitates of the $\tau-\mathrm{Fe}_{23}(\mathrm{C}, \mathrm{B})_{6}$ phase are formed. A satisfactory correlation is observed between the results of structure examinations and the calculated phase diagram Fe-C-B using the Thermo-Calc program [18] (Fig. 14). Laser alloying of $\mathrm{Ck} 45$ by means of borides: $\mathrm{CrB}, \mathrm{VB}_{2}$ and $\mathrm{B}_{4} \mathrm{C}$ increases the hardness HV to about $1200 \mathrm{HV}$ (Fig. 15). 

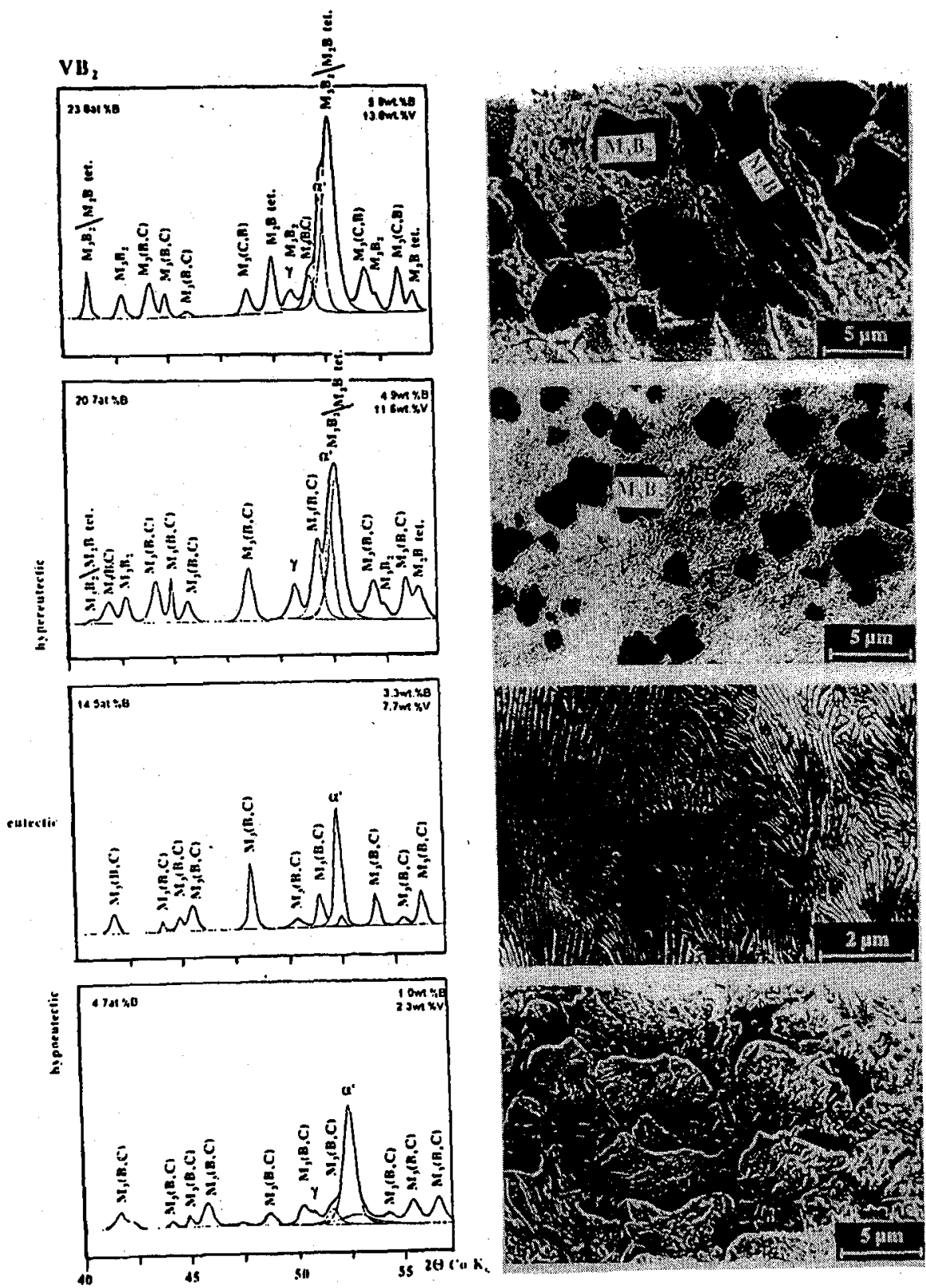

Fig. 12. $\mathrm{XRD}$ and microstructures of $\mathrm{VB}_{2}$ laser alloyed $\mathrm{Ck} 45$. 

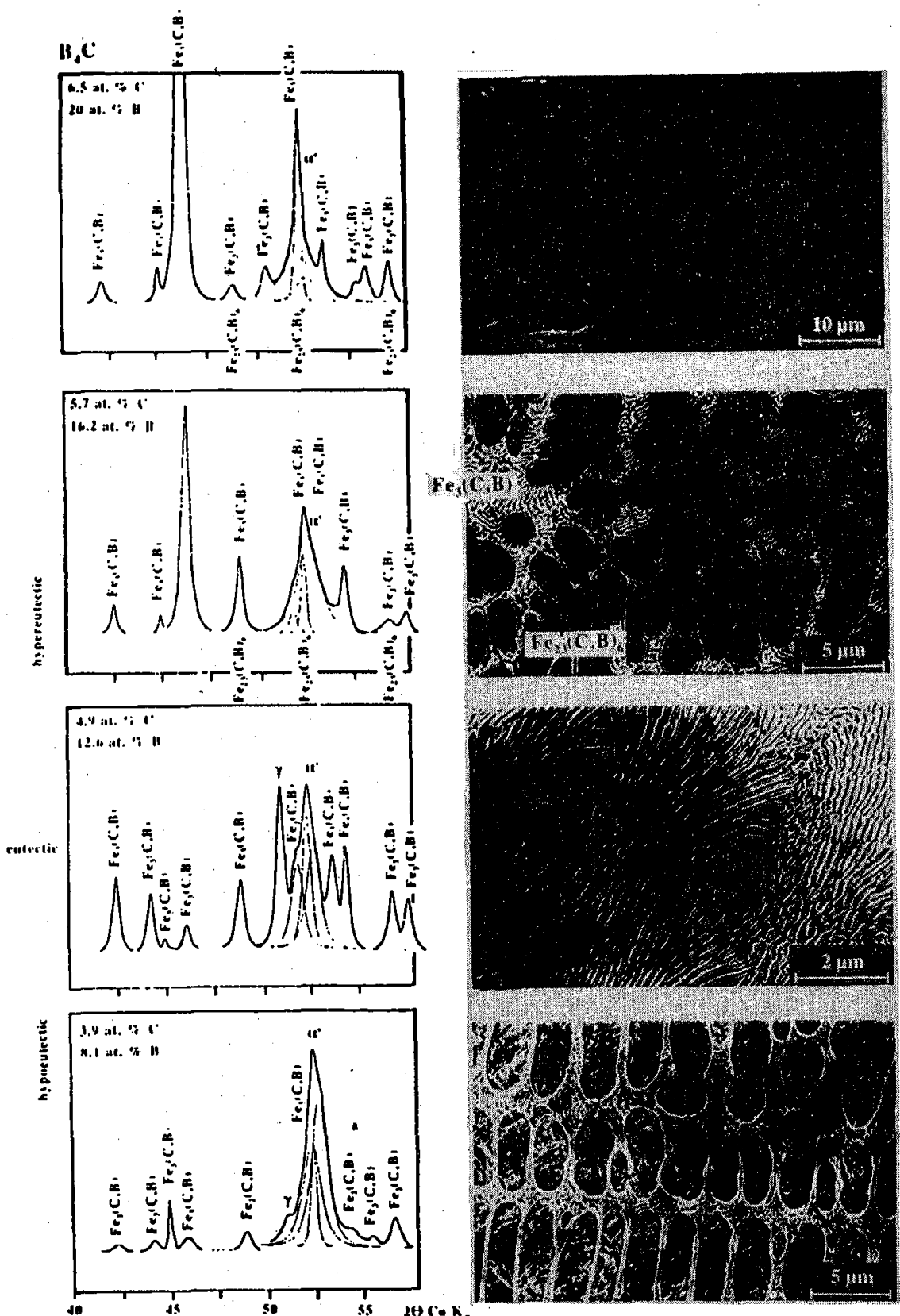

Fig. 13. XRD and microstructures of $\mathrm{B}_{4} \mathrm{C}$ laser alloyed $\mathrm{Ck} 45$. 

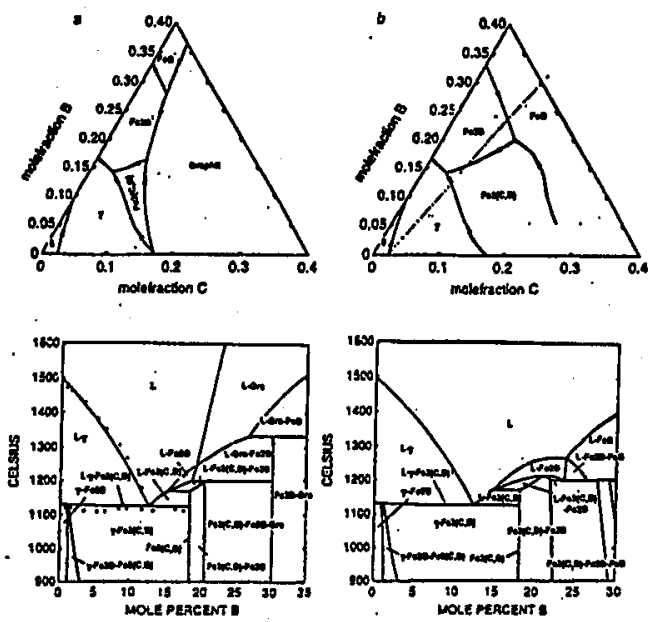

Fig. 14. Liquidus projection of Fe-B-C system at Fe-rich corner and cross-section along $\mathrm{Ck} 45+\mathrm{B}_{4} \mathrm{C}$ for equilibrium state (a) and by graphite suspension (b).

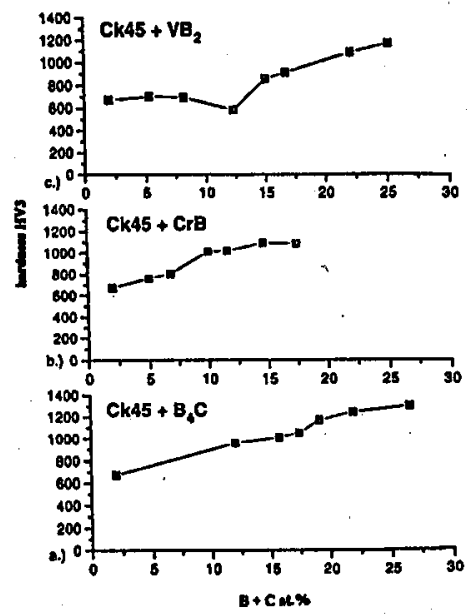

Fig. 15. Hardness $\mathrm{HV} 3$ of the $\mathrm{VB}_{2}, \mathrm{CrB}$ and $\mathrm{B}_{4} \mathrm{C}$ laser alloyed $\mathrm{Ck} 45$.

\section{Summary}

Examinations of influence of the laser remelting on the structure modification of aluminium alloys shows that the changes in solidification rate are manifested in the microstructure variation. The planar front of solidification is observed in $\mathrm{AlZn} 30$ alloy at the deep solid/liquid interface. A subsequent increase in solidification rate leads to the formation of cellular and later dendritic cells. Structure refinement is observed in a great scale for $\mathrm{Al}-\mathrm{Zn}, \mathrm{Al}-\mathrm{Fe}$ and $\mathrm{Al}-\mathrm{Si}$ alloys and for the $\mathrm{AlZn} 5 \mathrm{Mg} 3 \mathrm{Cu} 1$ alloy even a formation of the precipitates characteristic of rapid solidification can be seen. Laser remelting of constructional steels causes the formation of the fine martensite; moreover, a subsequent heating leading to 
overlapping of laser tracks results in the further martensite refinements. Laser alloying of M2 HSS using carbides $\mathrm{VC}$ or $\mathrm{Mo}_{2} \mathrm{C}$ leads to diminishing of the fraction of dendritic ferrite/martensite structures, while the fraction of retained austenite is raised. Precipitates of the primary carbides are observed for the hypereutectic compositions in laser tracks. Borides $\mathrm{CrB}$ or $\mathrm{VB}_{2}$ laser alloying of M2 HSS results in formation of the $\mathrm{M}_{23} \mathrm{~B}_{6}$ and $\mathrm{MB}$ phases, at higher concentrations of alloying elements. Laser modification using borides: $\mathrm{CrB}, \mathrm{VB}_{2}$ and $\mathrm{B}_{4} \mathrm{C}$ of $\mathrm{Ck} 45$ shows:

in the case of $\mathrm{CrB}$ alloying: formation of $\mathrm{M}_{3}(\mathrm{C}, \mathrm{B}) / \mathrm{M}_{2} \mathrm{~B}$ phases in eutectic and primary precipitates of $\mathrm{M}_{2} \mathrm{~B}$;

in the case of $V B_{2}$ alloying: formation of $\mathrm{M}_{3} \mathrm{~B}_{2}$ and $\mathrm{M}_{2} \mathrm{~B}$ phases;

in the case of $\mathrm{B}_{4} \mathrm{C}$ alloying: primary precipitates of $\tau-\mathrm{Fe}_{23}(\mathrm{C}, \mathrm{B})_{6}$ phase.

The calculated (using Thermo-Calc program) phase diagrams and the experimentally obtained results of structure examinations shows satisfactory agreement for the carbide laser alloying. Carbide and boride laser alloying could increase the hardness HV of the modified layers up to about $1200 \mathrm{HV}$.

\section{References}

[1] W.M. Steen, Laser Materials Processing, Springer Verlag, Berlin 1991.

[2] A. Pcrcz, J. Delafond, J.M. Pelletier, B. Vannes, Mater. Sci. Forum 59/60, 535 (1990).

[3] Proc. 5th Int. Conf. on Welding and Melting by Electron and Laser BEAMS CISFFEL, La Baule (France) 1993, Ed. E. Charoulet, Commisariat á l'Energie Atomique, Saclay 1993.

[4] Proc. NATO ASI "Laser Application for Mechanical Industry", Erice (Italy) 1992, "Ettore Majorana" Centre for Scientific Culture, Erice-Trapani-Sicily 1992.

[5] W. Kurz, R. Trevedi, Mater. Sci. Eng. A 179/180, 46 (1994).

[6] J. Kusinski, Metall. Trans. A 19, 377 (1988).

[7] A. Gremaud, M. Carrard, W. Kurz, Acta Metall. Mater. 38, 2587 (1990).

[8] B. Major, R. Ciach, R. Ebner, F. Jeglitsch, B. Kriszt, K. Rabitsch, Phys. Status Solidi A 141, 15 (1994).

[9] L. Ahman, Metall. Trans. A 15, 1829 (1984).

[10] N. Jost, Z. Met.k. 85, 9 (1994).

[11] A. Hirose, K.F. Kobayashi, Mater. Sci. Eng. A 174, 199 (1994).

[12] V. Synecek, B. Major, P. Bartuska, J. Lasek, M. Simerska, Z. Met.k. 83, 246 (1992).

[13] G. Hackl, R. Ebner, F. Jeglitsch, Z. Met.k. 83, 368 (1992).

[14] R. Ebner, in: Proc. 2nd Conf. on Advanced Materials and Processes, Cambridge, Eds. T.W. Clyne, P.J. Withers, Vol. 1, 1991, p. 115.

[15] B. Kriszt, R. Ebner, W. Tragl, B. Major, Prakt. Met. Sondebd. 26, 455 (1995).

[16] K. Rabitsch, R. Ebner, B. Major, Scr. Metall. Mater. 30, 253 (1994).

[17] R. Ebner, K. Rabitsch, B. Kriszt, B. Major, in: Proc. NATO ASI, Sesimbra (Portugal) 1994, Ed. R. Vilar, Instituto Superior Technica, Lisboa 1994, p. 875.

[18] K. Rabitsch, R. Ebner, B. Major, Prakt. Met. Sonderbd. 25, 509 (1994). 